\title{
Risk Factor Profile Of Young Adults With Acute Myocardial Infarction: A Preliminary Finding
}

Mohd Zhafri Mohd Razib ${ }^{1}$, Azarisman Shah M.Shah ${ }^{2}$, Jamalludin A.Rahman ${ }^{3}$, Aszrin Abdullah $^{4}$, Aida N.S M.Shah ${ }^{2}$, Norlelawati Abdul Talib ${ }^{5}$, Norbaiyah M.Bakrim ${ }^{4}$, Samsul Draman 6

${ }^{1}$ Department of Family Medicine, Kulliyyah of Medicine, International Islamic University Malaysia

${ }^{2}$ Department of Internal Medicine, Kulliyyah of Medicine, International Islamic University Malaysia

${ }^{3}$ Department of Community Medicine, Kulliyyah of Medicine, International Islamic University Malaysia

${ }^{4}$ Department of Basic Medical Sciences, Kulliyyah of Medicine, International Islamic University Malaysia

${ }^{5}$ Department of Pathology and Laboratory Medicine, Kulliyyah of Medicine, International Islamic University Malaysia

${ }^{6}$ Department of Family Medicine, Kulliyyah of Medicine, International Islamic University Malaysia, Pahang, Malaysia

Presenter: Mohd Zhafri Mohd Razib

Introduction: Acute myocardial infarction (AMI) is a major cause of death around the world. There are limited studies of risk factor profile in young adults with AMI. This study aimed to assess the risk factor profile of young adults with AMI at the emergency department of Hospital Tengku Ampuan Afzan (HTAA), Kuantan, Pahang. This is a preliminary result of young adults (age between 18 to 45 years old) who presented to the emergency department of HTAA. Materials and Methods: This cross-sectional study was conducted in HTAA from the $31^{\text {st }}$ July 2017 to the $11^{\text {th }}$ June 2018 involving 709 patients who were diagnosed with AMI. Seventy seven patients were less than 45 years old. However, only 55 were recruited for analysis who fulfilled the inclusion and exclusion criteria. Results: The prevalence of young adults with AMI was $10.9 \%$ with mean age of $38.8 \pm 5.1$ years old and $96.4 \%$ were male. Eighty percent of the patients were Malay followed by $10.9 \%$ Chinese and $9.1 \%$ were Indian. $83.6 \%$ were married while $14.5 \%$ were unmarried and $1.8 \%$ were divorcees. Majority of patients $(81.8 \%)$ had income less than RM4000. The common risk factors of young adults with AMI presented to HTAA was smoking $(80 \%)$ followed by increased waist circumference $(54.5 \%)$, obesity $(52.7 \%)$, hypertension (40\%), hypercholesterolaemia (27.2\%), family history of ischaemic heart disease $(27.2 \%)$, and diabetes mellitus (21.8\%). Conclusion: AMI in young adults almost exclusively occurs in male. Smoking and obesity were the most common risk factors in young adults with AMI in HTAA. 